\title{
ENRAIZAMENTO DE ESTACAS DOS PORTA-ENXERTOS \\ ARATICUM-DE-TERRA-FRIA (Rollinia sp.) E ARATICUM-MIRIM (Rollinia emarginata Schltdl.) PARA ANONÁCEAS
}

\author{
Rooting of rootstock cutting Araticum-de-Terra-Fria (Rollinia sp.) and Araticum-Mirim \\ (Rollinia emarginata Schltdl.) for anonáceas
}

\author{
José Emílio Bettiol Neto ${ }^{1}$, Rafael Pio ${ }^{2}$, Silvana Catarina Sales Bueno ${ }^{3}$, \\ Débora Costa Bastos ${ }^{4}$, João Alexio Scarpare Filho ${ }^{5}$
}

\begin{abstract}
RESUMO
Objetivou-se com o presente trabalho verificar a influência do ácido 3-indolbutírico (AIB) sobre o enraizamento de estacas de araticum-de-terra-fria e araticum-mirim. Estacas semilenhosas padronizadas com $15 \mathrm{~cm}$ de comprimento, um par de folhas e diâmetro de 0,4-0,5 cm, foram tratadas com diferentes concentrações de AIB $\left(0,1000,2000\right.$ e $\left.3000 \mathrm{mg} . \mathrm{L}^{-1}\right)$ por cinco segundos e, posteriormente, colocadas em bandejas de isopor de 72 células $\left(120 \mathrm{~cm}^{3} /\right.$ célula) contendo como substrato a vermiculita expandida de grânulos médios. Em seguida, as bandejas foram transferidas para câmara de nebulização intermitente. Após 60 dias do estaqueamento, avaliou-se a porcentagem de estacas vivas, calejadas, enraizadas, brotadas e o número médio de raízes por estaca. Concluiu-se que o araticum-deterra-fria promoveu melhores resultados para todas as variáveis analisadas, em comparação com o araticum-mirim; o AIB apenas influenciou a porcentagem de estacas calejadas, enraizadas e brotadas para o araticum-de-terra-fria, sendo que concentrações crescentes de AIB aumentam a porcentagem de estacas calejadas e enraizadas até a obtenção de $89 \%$ e $56,4 \%$, respectivamente, mas por outro lado diminuem linearmente a porcentagem de estacas brotadas.
\end{abstract}

Termos para indexação: Propagação, estaquia, ácido 3-indolbutírico e AIB.

\begin{abstract}
The objective of the present research to verify the was influence of the indol-3-butyric acid (IBA) on rooting of cutting of araticum-de-terra-fria and araticum-mirim. Semi hardwood cuttings standardized with $15 \mathrm{~cm}$ of length, one pair of leaves and diameter of $0,4-0,5 \mathrm{~cm}$, were treated with different concentrations of IBA $\left(0,1000,2000\right.$ and $\left.3000 \mathrm{mg} . \mathrm{L}^{-1}\right)$ for five seconds and later on placed in trays of polypropylene of 72 cells $\left(120 \mathrm{~cm}^{3}\right)$, containing as substrate vermiculita, being transferred to a camera of intermittent nebulization. After 60 days, the alive cutting, callous, rooting and sprouting percentages, and also, the number of rootses emitted by cutting were evaluated. The araticum-de-terra-fria promoted better results for all the analyzed variables, in comparison to araticummirim. IBA just influenced the callous, rooting and sprouting percentage for the araticum-de-terra-fria. Growing concentrations of IBA increased the callous and rooting percentage to the values of 89 and $56.4 \%$, respectively, but on the other hand, they lineally decreased sprouting percentage.
\end{abstract}

Index terms: Propagation, cutting, indol-3-butyric acid and IBA.

\section{(Recebido para publicação em 4 de outubro de 2005 e aprovado em 22 de maio de 2006)}

\section{INTRODUÇÃO}

A cultura da atemóia tem despertado grande interesse nos últimos anos no Brasil, por se tratar de uma deliciosa fruta, com características adequadas ao comércio e pertencente ao rol das frutas exóticas (TOKUNAGA, 2000). As iniciativas para explorar o potencial de mercado da atemóia ainda são bastante insuficientes, sobretudo, principalmente, por ser cultivada por pequenos produtores, pela inexistência de cultivares adaptadas às diversas regiões do País e pela escassez de informações sobre os sistemas de cultivo e pela importância econômica da atividade (MELLO et al., 2002).

Por tratar-se de um híbrido interespecífico, a produção de mudas via semente deve ser descartada devido à grande segregação que ocorre na geração F2, gerando um pomar heterogêneo e desuniforme, especialmente em relação ao porte das plantas, o que vem a dificultar os tratos culturais e fitossanitários. Assim, é recomendável o emprego de técnicas de propagação, como o método de enxertia tipo borbulhia e garfagem tipo inglês complicado (CAMPBELL \& PHILLIPS, 1994; FUENTES, 1999; TOKUNAGA, 2000).

\footnotetext{
${ }^{1}$ Engenheiro Agrônomo, Pesquisador Científico Centro APTA Frutas, Instituto Agronômico - IAC - Av. Luiz Pereira dos Santos, nº 1500, Corrupira 13214-820 - Jundiaí, SP - bettiolneto@iac.sp.gov.br

2 Engenheiro Agrônomo, Dr., Pesquisador Científico Centro APTA Frutas - Instituto Agronômico/IAC - rafaelpio@hotmail.com

${ }^{3}$ Engenheira Agrônoma, Dra., Núcleo de Produção de Mudas/CATI - São Bento do Sapucaí, SP - scsbueno@bol.com.br

${ }^{4}$ Engenheira Agrônoma, M.Sc., Doutoranda do curso de Fitotecnia - Departamento de Produção Vegetal - USP/ESALQ - dcbastos@esalq.usp.br

${ }^{5}$ Engenheiro Agrônomo, Dr., Professor do Departamento de Produção Vegetal - USP/ESALQ - jascarpa@esalq.usp.br
} 
De modo geral, as anonáceas são muito suscetíveis às podridões de raízes e de colo, razão pela qual é importante escolher um porta-enxerto adequado. A fruta-do-conde ou pinheira, quando utilizada como porta-enxerto, gera plantas compactas, ideais para a condução comercial, porém com o inconveniente de ser suscetível às podridões radiculares, limitando assim consideravelmente sua utilização. Portanto, a condessa apresenta a vantagem de ser um pouco mais tolerante às podridões radiculares, porém dois anos após a enxertia, tem-se observado uma notável incompatibilidade entre o enxerto e o porta-enxerto. Vários porta-enxertos da família das anonáceas podem ser utilizados, porém alguns, apresentam incompatibilidade na enxertia (CAMPBELL \& PHILLIPS, 1994).

Para evitar problemas com segregação e incompatibilidade entre enxerto e porta-enxerto, uma alternativa é o emprego do araticum-mirim (Rollinia emarginata Schltdl.) ou o araticum-de-terra-fria (Rollinia sp.) como porta-enxertos, pois têm demonstrado boa compatibilidade e resistência a fungos de solo e por serem menos atrativos às brocas que atacam o colo das plantas. $\mathrm{O}$ araticum-mirim induz nanismo da copa e é de ocorrência natural nas baixadas, próximo a cursos de água. $\mathrm{O}$ araticumde-terra-fria induz maior vigor a copa, comparadas às plantas enxertadas sobre o araticum-mirim, com ocorrência natural em altitudes acima de $950 \mathrm{~m}$. Alguns produtores acreditam que as mudas enxertadas sobre araticum-deterra-fria não apresentam boa performance em regiões mais quentes, devido ter sua origem em regiões mais frias (BONAVENTURE, 1999; TOKUNAGA, 2000).

A propagação de várias espécies frutíferas por estaquia tem sido sugerida por vários autores, porém, os resultados são variáveis em função de fatores internos e externos que influenciam o processo de enraizamento de estacas. Destacam-se como fatores internos, a condição fisiológica da planta matriz, idade da planta, tipo de estaca, época do ano para coleta, potencial genético do enraizamento, sanidade do material e balanço hormonal (FACHINELLO et al., 1995).

Tem-se observado que o enraizamento de estacas em espécies lenhosas de difícil enraizamento pode ser conseguido se forem fornecidos fatores adequados para o enraizamento das mesmas. A busca de técnicas auxiliares, como o uso de reguladores de crescimento, tem sido utilizada com freqüência, a fim de proporcionar melhoria no enraizamento (BIASI, 1996). O uso de reguladores de crescimento tem por finalidade aumentar a porcentagem de estacas enraizadas, acelerar a iniciação radicular, aumentar o número e a qualidade das raízes formadas e uniformizar o enraizamento (FACHINELLO et al., 1995).

O grupo de reguladores de crescimento usado com maior frequiência é o das auxinas (HINOJOSA, 2000). De acordo com Hartmann et al. (2002), dentre os vários grupos de reguladores de crescimento, as auxinas são as que desempenham maiores funções no enraizamento de estacas. Dentre as principais funções biológicas das auxinas, pode-se citar a ontogênese, especialmente as raízes. A auxina natural é sintetizada principalmente em gemas apicais e em folhas jovens e, de maneira geral, movese através da planta, do ápice para a base. $\mathrm{O}$ ácido 3indolbutírico (AIB) é a auxina sintética mais comumente utilizada na indução do enraizamento adventício. Por apresentar propriedade de promover a formação de primórdios radiculares, o AIB tem sido utilizado para induzir o enraizamento em numerosas espécies vegetais (AWAD \& CASTRO, 1989; PASQUAL et al., 2001).

A potencialidade de uma estaca formar raízes é variável com a espécie e também com a cultivar (FACHINELLO et al., 1995). Há evidências de que o enraizamento por estacas seja controlado geneticamente (HAISSIG, 1982).

A carência de trabalhos que envolvam a multiplicação vegetativa de porta-enxertos para anonáceas foi a razão pela qual este trabalho foi realizado, buscando verificar a influência do o AIB sobre o enraizamento de estacas de araticum-de-terra-fria e araticum-mirim.

\section{MATERIAL E MÉTODOS}

O presente trabalho foi realizado nas dependências do Centro Avançado de Pesquisa Tecnológica do Agronegócio de Frutas do Instituto Agronômico (IAC), situado no município de Jundiaí-SP.

Foram coletadas estacas semilenhosas de plantas matrizes de araticum-de-terra-fria e araticum-mirim, padronizadas com $15 \mathrm{~cm}$ de comprimento, um par de folhas e diâmetro de 0,4-0,5 cm. Após o preparo das estacas, imergiu-se a base das mesmas em diferentes concentrações de $\operatorname{AIB}\left(0,1000,2000\right.$ e $\left.3000 \mathrm{mg} . \mathrm{L}^{-1}\right)$ por cinco segundos, sendo as mesmas, posteriormente, colocadas em bandejas de poliestireno de 72 células $\left(120 \mathrm{~cm}^{3} /\right.$ célula) contendo como substrato vermiculita expandida de grânulos médios. Em seguida, as bandejas foram transferidas para câmara de nebulização intermitente (temperatura de $25 \pm 5^{\circ} \mathrm{C}$, UR média de $72 \%$, tempo de aspersão de 20 segundos em intervalos de 10 minutos).

O delineamento utilizado foi o inteiramente casualizado, em esquema fatorial $2 \times 4$, sendo o primeiro

Ciênc. agrotec., Lavras, v. 30, n. 6, p. 1077-1082, nov./dez., 2006 
fator constituído pelos dois porta-enxertos e o segundo fator pelas diferentes concentrações de AIB, com quatro repetições e dez estacas por unidade experimental. Após 60 dias, avaliou-se a porcentagem de estacas vivas, calejadas, enraizadas, brotadas e o número médio de raízes por estaca.

Os dados foram submetidos à análise de variância, as médias ao teste Tukey e as concentrações de AIB à regressão (GOMES, 2000). As análises estatísticas foram realizadas pelo programa computacional Sistema para Análise de Variância - SISVAR (FERREIRA, 2000).

\section{RESULTADOS E DISCUSSÃO}

De acordo com a análise estatística, verificou-se que houve diferença significativa entre os porta-enxertos para todas as variáveis analisadas e apenas efeito das concentrações de AIB para a porcentagem de estacas enraizadas, calejadas e brotadas no porta-enxerto araticum-de-terra-fria.

Na comparação do desempenho rizogênico das estacas de ambos os porta-enxertos, verificou-se que o araticum-de-terra-fria promoveu melhores resultados para todas as variáveis analisadas, em comparação com o araticum-mirim. Não houve quaisquer estaca brotada e enraizada para o araticum-mirim, apesar de ter ocorrido uma pequena porção de estacas calejadas (Tabela 1).

A formação de raízes adventícias em estacas pode ser direta e indiretamente controlada por genes (HAISSIG \& REIMENSCHNEIDER, 1988). Segundo estes autores, o aspecto genético que influencia o processo de enraizamento de estacas não tem sido investigado. A potencialidade de uma estaca em formar raízes é variável com a espécie e cultivar, podendo ser feita uma classificação entre espécies ou cultivares de fácil, médio ou difícil capacidade de enraizamento, ainda que a facilidade de enraizamento seja resultante da interação de diversos fatores e não apenas do potencial genético (FACHINELLO et al., 1995).

Em uma análise comparativa entre os portaenxertos em questão, o araticum-de-terra-fria apresentou $83,12 \%$ de estacas vivas contra $40 \%$ do araticum-mirim, diferença de $43,12 \%$. Analisando-se as relações entre as variáveis: porcentagem de estacas enraizadas e porcentagem de estacas vivas, porcentagem de estacas enraizadas e porcentagem de estacas calejadas e porcentagem de estacas calejadas e porcentagem de estacas vivas, para o araticum-de-terra-fria, detectou-se que $51,87 \%$ das estacas vivas enraizaram, 59,74\% das estacas calejadas enraizaram e $87,22 \%$ das estacas vivas calejaram (Tabela 1). Através dessas relações, nota-se que o araticum-de-terra-fria possui elevado potencial rizogênico em suas estacas, porém medidas alternativas devem ser tomadas a fim de aumentar a porcentagem de enraizamento, igualando assim a porcentagem de calejamento com a de enraizamento das estacas.

Por meio da análise de regressão para as concentrações de AIB, verificou-se que houve crescimento linear para a porcentagem de estacas enraizadas e calejadas para o araticum-de-terra-fria, em função do aumento das concentrações de AIB, obtendose $56,4 \%$ de estacas enraizadas e $89 \%$ de estacas calejadas com a utilização de 3000 mg.L-1 do fitoregulador (Figura $1 \mathrm{~A}$ e 1B). Esses resultados concordam com Blat et al. (2002), que obtiveram $60 \%$ de estacas enraizadas de araticum-de-terra-fria, com a utilização de AIB. Segundo Carpenter \& Cornell (1992) e Hartmann et al. (2002), a aplicação exógena de auxina pode proporcionar maior taxa de estacas enraizadas, aumentar o número de raízes e a uniformidade de enraizamento.

TABELA 1 - Porcentagem de estacas vivas (PEV), enraizadas (PEE), calejadas (PEC), brotadas (PEB) e número médio de raízes por estacas (NRE) de porta-enxertos para anonáceas. Centro Avançado de Pesquisa Tecnológica do Agronegócio de Frutas (CAPTA Frutas/IAC), Jundiaí-SP, 2005.

\begin{tabular}{|c|c|c|c|c|c|}
\hline \multirow{2}{*}{ Porta-enxerto } & \multicolumn{5}{|c|}{ Variáveis analisadas* } \\
\hline & PEV & PEE & PEC & PEB & NRE \\
\hline Araticum-de-Terra-Fria & 83,12 a & 43,12 a & $72,50 \mathrm{a}$ & 15,62 a & $4,27 \mathrm{a}$ \\
\hline Araticum-Mirim & 40,00 & 0,00 & $8,67 \quad b$ & 0,00 & $0,00 \quad b$ \\
\hline $\mathrm{cv}(\%)$ & 26,42 & 23,69 & 23,77 & 54,77 & 25,88 \\
\hline
\end{tabular}

* Médias seguidas pela mesma letra na coluna não diferem estatisticamente entre si, pelo teste Tukey, ao nível de 5\% de probabilidade. 
Por outro lado, houve decréscimo linear para a porcentagem de estacas brotadas conforme se submeteu às estacas em concentrações crescentes do fitoregulador, obtendo-se 27,25\% de estacas brotadas na ausência de tratamento com AIB (Figura 1C). Este comportamento pode estar ligado ao fato da aplicação exógena de AIB promover um desbalanceamento das substâncias presentes internamente nas estacas, promovendo assim um favorecimento ao enraizamento pelo suplemento de auxina, mas conseqüentemente, um desfavorescimento do crescimento das brotações. Esses resultados são similares aos obtidos por Pio et al. (2003) e Rufini et al. (2002), nos quais a aplicação crescente de concentrações de AIB promoveram queda linear para a porcentagem de estacas brotadas de maracujazeiro doce (Passiflora alata Dryand) e azedo (Passiflora edulis f.flavicarpa Deneger), mas por outro lado aumentou linearmente a porcentagem de estacas enraizadas.
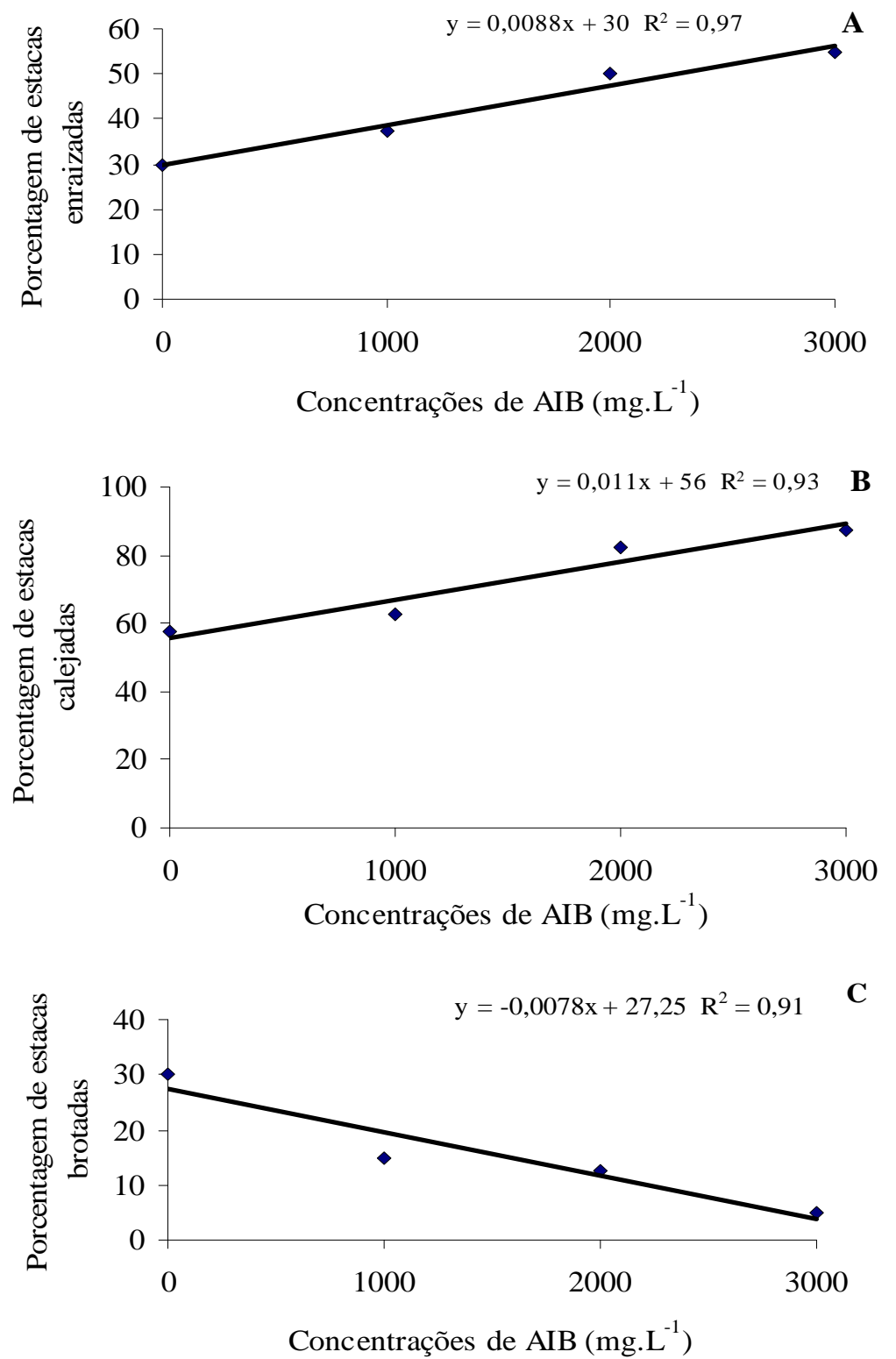

FIGURA 1 - Porcentagem de estacas enraizadas (A), calejadas (B) e brotadas (C) do porta-enxerto para anonáceas araticumde-terra-fria. Centro Avançado de Pesquisa Tecnológica do Agronegócio de Frutas (CAPTA Frutas/IAC), Jundiaí-SP, 2005.

Ciênc. agrotec., Lavras, v. 30, n. 6, p. 1077-1082, nov./dez., 2006 


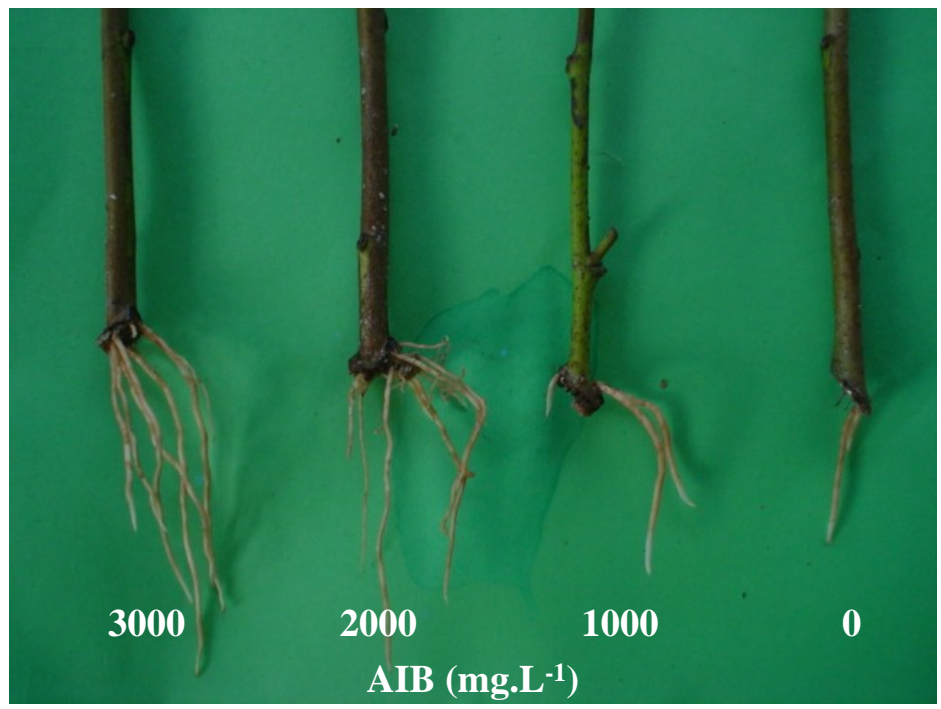

FIGURA 2 - Detalhe do potencial de enraizamento das estacas de araticum-de-terra-fria, quando submetidas às diferentes concentrações de AIB. Centro Avançado de Pesquisa Tecnológica do Agronegócio de Frutas (CAPTA Frutas/IAC), Jundiaí-SP, 2005.

\section{CONCLUSÕES}

Os materiais analisados apresentam comportamentos diferenciais em relação ao enraizamento de suas estacas, destacando-se a melhor performance de enraizamento do araticum-de-terra-fria;

$\mathrm{O}$ araticum-de-terra-fria responde de forma positiva às concentrações de $\mathrm{AIB}$, com aumentos na porcentagem de estacas calejadas e enraizadas, mas por outro lado, diminuem com reduções lineares na porcentagem de estacas brotadas;

O AIB foi ineficiente na rizogênese do porta-enxerto araticum-mirim, sugerindo-se novos estudos envolvendo concentrações e tempo de imersão da estaca em soluções deste regulador;

\section{REFERÊNCIAS BIBLIOGRÁFICAS}

AWAD, M.; CASTRO, P. Introdução à fisiologia vegetal. São Paulo: Nobel, 1989. 177 p.

BIASI, L. A. Emprego do estiolamento na propagação de plantas. Ciência Rural, Santa Maria, v. 26, n. 2, p. 309-315, 1996.

BLAT, S. F.; BUENO, S. C. S.; SCARPARE FILHO, J. A.; MEDEIROS, F. D. Desempenho de cultivares de atemóia enxertadas sobre duas espécies do gênero Rollinia, propagadas por semente e por estaca. In: CONGRESSO
BRASILEIRO DE FRUTICULTURA, 17., 2002, Belém. Anais... Belém: Embrapa, 2002. CD-ROM.

BONAVENTURE, L. The cultivation of the cherimoya and of its hybrid atemoya in Brazil. Acta Horticulturae, The Hague, v. 497, p. 143-146, 1999.

CAMPBELL, C. W.; PHILLIPS, R. L. The atemoya. Gainesville: University of Florida, 1994. (Fruit crops Fact Sheet FC-64).

CARPENTER, W. J.; CORNELL, J. A. Auxin application duration and concentration govern rooting of hibiscus stem cuttings. Journal of the American Society for Horticultural Science, Alexandria, v. 117, n. 1, p. 68-74, 1992.

FACHINELLO, J. C.; HOFFMANN, A.; NACHTIGAL, J. C.; KERSTEN, E.; FORTES, G. R. de L. Propagação de plantas frutíferas de clima temperado. 2. ed. Pelotas: UFPel, 1995. $179 \mathrm{p}$.

FERREIRA, D. F. Análise estatística por meio do SISVAR (Sistema para Análise de Variância) para Windows versão 4.0. In: REUNIÃO ANUAL DA REGIÃO BRASILEIRA DA SOCIEDADE INTERNACIONAL DE BIOMETRIA, 45., 2000, São Carlos. Anais... São Carlos: UFSCar, 2000. p. 255258. 
FUENTES, J. L. Production of cherimoya (Annona cherimola Mill.) in Ecuador. Acta Horticulturae, The Hague, v. 497, p. 59-63, 1999.

GOMES, F. P. Curso de estatística experimental. 14. ed. Piracicaba: USP/ESALQ, 2000. 477 p.

HAISSIG, B. E. Carbohydrate and amino acid concentration during adventitious root primordium development in Pinus banksiana Lamb. cutting. Foresty Science, [S.1.], v. 28, p. 813-821, 1982.

HAISSIG, B. E.; REIMENSCHNEIDER, E. D. Genetic effects on adventitious rooting. In: DAVIS, T. D.; HAISSIG, B. E.; SANKLHA, N. (Eds.). Adventitious root formation in cuttings. Portland: Discorides, 1988. p. 47-60.

HARTMANN, H. T.; KESTER, D. E.; DAVIES JUNIOR, F. T.; GENEVE, R. L. Plant propagation: principles and practices. 7. ed. New Jersey: Prentice Hall, 2002. 880 p.

HINOJOSA, G. F. Auxinas. In: CID, L. P. B. Introdução aos hormônios vegetais. Brasília, DF: Embrapa, 2000. p. $15-54$.
MELLO, N. T. C. de; NOGUEIRA, E. A.; MAIA, M. L. Atemóia: a fruta que vem conquistando os consumidores brasileiros. In: CONGRESSO BRASILEIRO DE FRUTICULTURA, 17., 2002, Belém. Anais... Belém: Embrapa, 2002. CD-ROM.

PASQUAL, M.; CHALFUN, N. N. J.; RAMOS, J. D.; VALE, M. R. do; SILVA, C. R. de R. e. Fruticultura comercial: propagação de plantas frutíferas. Lavras: UFLA/FAEPE, 2001. $137 \mathrm{p}$.

PIO, R.; RUFINI, J. C. M.; RAMOS, J. D.; GONTIJO, T. C. A.; CARRIJO, E. P. Propagação do maracujazeiro amarelo (Passiflora edulis f. flavicarpa Deneger) por estaquia utilizando-se sacarose e ácido indolbutírico. Revista Científica Rural, Bagé, v. 8, n. 1, p. 129-134, 2003.

RUFINI, J. C. M.; PIO, R.; RAMOS, J. D.; GONTIJO, T. C. A.; MENDONÇA, V.; COELHO, J. H. C.; ALVARES, B. F. Influência da sacarose e do ácido indol-butírico na propagação do maracujazeiro-doce por estaquia. Revista Científica Rural, Bagé, v. 7, n. 2, p. 122-127, 2002.

TOKUNAGA, T. A cultura da atemóia. Campinas: CATI, $2000.80 \mathrm{p}$. 